\title{
Adult Central Nervous System Teratoma
}

National Cancer Institute

\section{Source}

National Cancer Institute. Adult Central Nervous System Teratoma. NCI Thesaurus.

Code C5794.

A mature or immature teratoma affecting the central nervous system and occurring in adults. 